\title{
Effectiveness of Morita Therapy-Based Consultation for a School-Refusing Adolescent with Psychogenic Fever
}

\author{
Naoki Maeda \\ Correspondence: Naoki Maeda, Kyushu University of Health and Welfare, 1714-1 Yoshino, Nobeoka, Miyazaki, \\ 882-8508, Japan.
}

Received: September 26, 2017

Accepted: October 24, $2017 \quad$ Online Published: October 29, 2017

doi:10.11114/jets.v5i12.2671

URL: https://doi.org/10.11114/jets.v5i12.2671

\begin{abstract}
Morita therapy, developed by Shoma Morita (1874-1938) in Japan, is a type of psychotherapy that has been applied to deal with neurotic symptoms. This therapeutic approach is based on the conviction that neurotic symptoms are universal issues that eventually subside if the symptoms are accepted and everyday activities are carried out. By examining a school-refusing female adolescent suffering from somatic complaints (mainly psychogenic fever), the present study explores the effectiveness of Morita therapy-based consultation on the adolescent's school refusal tendencies. The findings indicate that, after the school counselor provided Morita therapy-based consultation to the parents of the school-refusing adolescent and the school staff members, the adolescent returned to school and psychogenic fever became afebrile after several days of resuming regular school attendance. The implication of the results is that Morita therapy can be effective for dealing with school-refusing adolescents suffering from neurotic symptoms.
\end{abstract}

Keywords: Morita therapy, school refusal, school-based consultation

\section{Introduction}

\subsection{Morita Therapy}

Morita therapy, developed by Shoma Morita (1874-1938) in Japan, is a form of psychotherapy that has been applied to deal with neurotic disorders (Ishiyama, 1986), including obsessive compulsive disorder, panic disorder, anxiety disorders, and psychosomatic disorders (Kora, 1989). This therapeutic approach is based on the belief that mood-related problems (e.g., anxiety, fear, or somatic symptoms) are universal human issues that eventually subside if the symptoms are accepted and routine activities are carried out (Ishiyama, 1983; Kanahara, 2008). However, neurotic patients tend to obsess about their symptoms and attempt to eliminate/control them, which only aggravates the symptoms. As a result, they continue to focus on their symptoms, which only leads to more aggravations. This vicious cycle of symptom amplification is referred to as "psychic interaction" (Miura \& Usa, 1970; Ogawa, 2013), which can also trigger patients' avoidance behaviors, due to situations that elicit feelings of anxiety, fear, stress, and so on. Moreover, the patients tend to have an unproductive mood- or physical condition-based lifestyle (Kanahara, 2008) that frequently omits practical actions, due to their prioritization of mood or somatic complaints. Therefore, in Morita therapy, the clients are encouraged to change their mood-based attitude into a purpose-based attitude, while accepting their neurotic symptoms and continuing their routine activities in daily life. Unlike other psychotherapies, such as cognitive behavior therapy (CBT), Morita therapy does not focus on reducing mood-related symptoms, but improving a client's lifestyle by taking necessary actions (Nakamura, 2005; Okamoto, 2015).

Morita therapy consists of residential and outpatient approaches, both of which are generally applied in therapists' didactic guidance and behavior instructions to reduce patients' self-focused attention and enhance their daily productive activities (Ishiyama, 1990). Recently, outpatient-based Morita therapy has become increasingly popular compared to inpatient treatment (Ishiyama, 2003; Nakamura, 2014). Overall, the treatment under Morita therapy can be classified in two parts (Kitanishi, 2005): (1) cognitive intervention aimed at making clients understand that they cannot avoid feelings of anxiety/fear due to the psychic interaction, even if they attempt to eliminate/control them; and (2) behavioral intervention aimed forcing patients to take necessary actions, while suffering from their anxiety-related symptoms. The latter, referred as "Kyofu totsunyu" or in vivo exposure, deals with the target behavior in CBT (Kitanishi, 2005). In sum, under Morita therapy, patients are instructed to accept their anxiety-based symptoms and take necessary actions (as the target behavior in their daily life) such as valuing their work or duty (Morioka, 2005). 


\subsection{Application of Morita Therapy for School Refusal}

School refusal refers to children's and adolescents' difficulty in attending school, based on emotional distress (Heyne \& Sauter, 2013). Previous studies have shown that somatic complaints associated with emotional distress are common features of school refusers (Honjo, Kasahara, \& Ohtaka, 1992), and in some cases, headaches, stomach aches, nausea, fever, and vomiting have been reported (Blagg, 1987; Heyne \& King, 2004). General clinical interventions for school refusal have mainly focused on CBT, which has provided clear evidence regarding its overall effectiveness (Bernstein, Hektner, Borchardt, \& McMillan, 2001; Heyne et al., 2002; Maynard et al., 2015; Last, Hansen, \& Franco, 1998; Ollendick \& King, 1999; Wimmer, 2008). CBT for school refusal generally employs psychoeducation, cognitive restructuring, contingency contracting, parental-management strategies, and exposure, all of which are based on a detailed assessment and functional analysis of the child and his/her parents (King \& Bernstein, 2001). In addition, CBT aims to reduce the child's anxiety symptoms or feelings of discomfort in school applying techniques that eventually increase his/her school attendance. In sum, CBT attempts to control anxiety-related symptoms, through cognitive behavioral techniques, and increase the patients' school attendance (King, Ollendick, \& Tonge, 1995).

Conversely, Morita therapy for school refusal is rather simple; that is, the patient is simply instructed to attend school immediately, while accepting his/her school-related-neurotic symptoms (Kanahara, 2008). In other words, the neurotic symptoms are not the subjects of immediate treatment, but the patient is encouraged to develop a purpose-based attitude by focusing on school attendance as the main task in his/her daily life (Kanahara, 2008). Such an instructive approach can be helpful for supporting school-refusing adolescents, especially when the school setting itself is the primary cause of concern.

In general, many school refusers avoid individual sessions at school, until their anxiety-related symptoms are either reduced or eliminated. In this regard, the parents (mostly the mothers) or school staff members visit the school counselor or psychologist, who then discusses an indirect intervention that does not include interviewing the students or conducting any direct assessments (Maeda, 2016). When the school counselor or psychologist provides such school-based support, consultation with the school staff members and parents is an essential part of the process. Morita therapy-based consultation may be applied, due to its didactic and psychoeducational approach. However, to date, there are relatively few case reports of Morita therapy-based consultation for school refusal, although there are many cases to which it can be effectively applied.

Therefore, the present study explores the effectiveness of Morita therapy-based consultation for school refusal by focusing on a school-refusing female adolescent suffering from somatic complaints (mainly psychogenic fever). The consultation was offered to the parents of the school-refusing female as well as to the school staff members at the junior high school where she is enrolled.

\section{Method}

\subsection{Case Presentation}

Student A is a 14-year-old (eighth grade) Japanese female student enrolled in a local public junior high school. Her family includes her father, mother, and two older brothers. Her father is employed as a business manager, whereas her mother is a full-time housewife. Student A has a cheerful personality, high intelligence, and many friends from early childhood. When Student A was in the sixth grade (12 years of age), she refused to attend school for two consecutive weeks, due to a personal problem. After resolving the issue, she was able to return to school immediately. Approximately 1 month after entering seventh grade (13 years of age), she was unable to attend school for five consecutive days, due to a high fever each morning. However, after a medical examination, the results showed that Student A did not have any particular physical disorder. In fact, her fevers would disappear after the decision was made to skip school and they never returned for the remainder of each day. Subsequently, she attended counseling sessions at a psychiatric clinic, where the psychotherapist advised Student A and her parents to "wait and see" until her symptoms (psychogenetic fever) subside, without encouraging her to attend school. However, this approach exacerbated Student A's psychogenetic fever and school non-attendance. Overall, the number of absences from school in the seventh grade (from April 2012 to March 2013) was 95 out of the 206 school days (46.1\%).

From the beginning of the eighth grade (April 2013; in Japan, the school year begins in April), a gradual school-return approach, developed by the school staff members and her parents was implemented for Student A. During the intervention, the homeroom teacher visited Student A's house and encouraged her to attend school with her parents the following morning. After arriving at school, Student A was provided with a special room, in which she received 50-minute tutorial sessions each day. This approach continued for approximately 6 months (April to September 2013). During this period, although her number of absences decreased to 9 out of the 92 school days, she was still unable to attend any classes in the classroom. 
In the seventh month of eight grade (October 2013), the number of Student A's absences from school increased once again, due to an intermittent recurrence of psychogenic fever in the mornings. From October to December 2013, even if she attended school without having a fever, her time spent in the individual tutorial room decreased from 50 minutes to 30 a day, due to her overall bad mood. As a result, the number of absences during this period reached 14 out of the 57 school days. In this situation, the mother was reluctant to encourage Student A to attend school and began thinking about transferring her to another school. Student A, who was also interested in such a transfer, went to observe another school in January 2014. However, she was unable to make a decision, after which her intermittent school attendance continued. Thus, in January 2014, the principal of the school asked the author (who worked as a part-time school counselor in another public school) to provide consultation regarding Student A's school refusal.

\subsection{Morita Therapy-Based Consultation}

On January 30, 2014, the parents, school counselor, homeroom teacher, and school principal held a support meeting regarding Student A's school refusal. During the meeting, the school counselor provided Morita therapy-based psychoeducation for Student A's symptoms and school refusal to her parents and the school staff members. The main contents of the psychoeducation included the following: (1) Student A's psychogenetic fever was reinforced and fixated by "psychic interaction" in which she and her parents continuously attempted to eliminate/control the fever; (2) her parents carried out a mood- and physical condition-oriented approach in which they avoided sending Student A to school when she had psychogenic fever or was simply in a bad mood; (3) Student A and her parents should change their attitude from a mood- and physical condition-based approach to a purpose-based approach in which Student A should attend school even if she has psychogenic fever in the morning; and (4) her parents should explain the concept of Morita therapy to their daughter and force her to attend school immediately, while ignoring her somatic complaints. After the school counselor explained the mechanisms of Student A's symptoms and the Morita therapy-based approach to her parents and the school staff members, they immediately accepted the approach. Immediately after the meeting, the parents described the contents of the consultation to their daughter.

\section{Results}

\subsection{Day 1: January 31, 2014 (Friday)}

Student A did not report any somatic complaints, and her body temperature was 36.1 degrees Celsius (C). Students A arrived at school with her mother at 7:20 a.m., after which she went to the classroom with her friends. Subsequently, she participated in six classes without any problems. According to the classroom teacher, Student A enjoyed having a chat with her classmates during lunch and did not show any neurotic symptoms. After the last class, Student A came home with her mother. The mother then told the school staff members that Student A had accepted the Morita therapy-based approach when her parents conveyed it to her. Students A also told her parents that she prepared herself for school, even though she had a fever.

\subsection{Day 2: February 3, 2014 (Monday)}

Student A did not report any somatic complaints and her body temperature was 36.1 degrees $\mathrm{C}$ before attending school. She arrived at school with her mother at 7:10 a.m. According to her mother, her daughter was in good physical condition and she had completed her homework assignments over the weekend. Student A participated in all the classes, as she did on the previous Friday. The staff members reported that her condition was stable during the classes. Student A reported (in a diary for the homeroom teacher) that, although she became anxious before attending the classes on the first day, she was relieved that she was able to stay all day without feeling uncomfortable.

\subsection{Day 3: February 4, 2014 (Tuesday)}

Student A arrived at school with her mother at 7:10 a.m. The homeroom teacher reported that she looked "gloomy" and frequently coughed, although there was no sign of a fever. Despite the teachers' concern, Student A attended all her classes without complaining of any physical or psychological problems. She left school with her mother at 4:30 p.m.

\subsection{Day 4: February 5, 2014 (Wednesday)}

The mother called the school at 6:55 a.m. and stated that Student A had a high fever and a headache. The school counselor told the mother that they should go see the doctor, after which the medical examination found no apparent problem. Upon returning home, Student A's temperature dropped to 36.1 degrees C. The school counselor then advised the mother to escort her daughter to school for the afternoon. At that time, although Student A's temperature increased to 38 degrees $\mathrm{C}$, the school counselor still advised the mother to bring her daughter to school. Student A arrived at school with her mother at 1:35 p.m., and she participated in all the remaining classes.

\subsection{Day 5: February 6, 2014 (Thursday)}

Student A arrived at school with her mother at 7:10 a.m., after which she participated in the first and second classes. 
After the second class, she visited the nurse's office, due to somatic complaints. Her temperature was 38.5 degrees C, and the school nurse decided to let Student A lie down and rest during the third class. During the fourth class, she returned to the classroom, despite having a fever of 37.6 degree C. Student A participated in the rest of classes without complaining of any physical or psychological problems. She left school with her mother at 4:30 p.m.

3.6 From Day 6 to Day 10: From February 7 (Friday) to 11 (Tuesday), 2014

The school was closed, due to a flu outbreak during this period. Student A also had the flu and remained in bed for several days.

\subsection{Day 11: February 12, 2014 (Wednesday)}

The mother reported that Student A's temperature was 39.0 degrees C. The school counselor told the mother that they should go see the doctor and take her daughter to school if no medical problems are found. This was also to confirm that Student A did not have the flu. After medical examination, the doctor found no apparent problems, after which the mother took her daughter to school at 11:30 a.m., just in time for the fourth class. After lunch, Student A's temperature decreased to 37.5 degrees $\mathrm{C}$, and she participated in the remaining afternoon classes without any issues. After school she walked home from school alone.

\subsection{Day 12: February 13, 2014 (Thursday)}

The mother reported that, although Student A did not have a fever, she complained of stomach pains and remained in the bathroom for a while. The school counselor advised the mother to take her daughter to school as soon as possible. Student A arrived at school with her mother at 7:30 a.m. and participated in all the classes. This was the final day that Student A reported somatic complaints and an unwillingness to attend school.

\subsection{From Day 13 to Day 21: February 17 (Monday) to 28 (Friday), 2014}

During this period, Student A attended school and took all her classes without complaining of any physical or psychological symptoms. In addition, Student A's psychogenetic fever was no longer reported. The mother kept taking her daughter to and from school every day. Student A also reported that she could regulate her daily life and felt completely well. Therefore, at the end of February, the school counselor decided to terminate the consecutive consultations and advised her to keep consulting with the school staff members, as a precaution.

\subsection{From February 2014 to March 2015 (13 Months)}

For approximately 1 month after the termination of the consecutive consultations, Student A maintained regular school attendance. From April 2014 on, Student A (in the ninth grade) was able to attend school without being escorted by her mother. However, the school counselor kept collecting her school attendance data until the end of the ninth grade (March 2015). Overall, she missed 7 out of the 200 school days, and she was able to continue on at her first choice of high school.

\section{(day)}

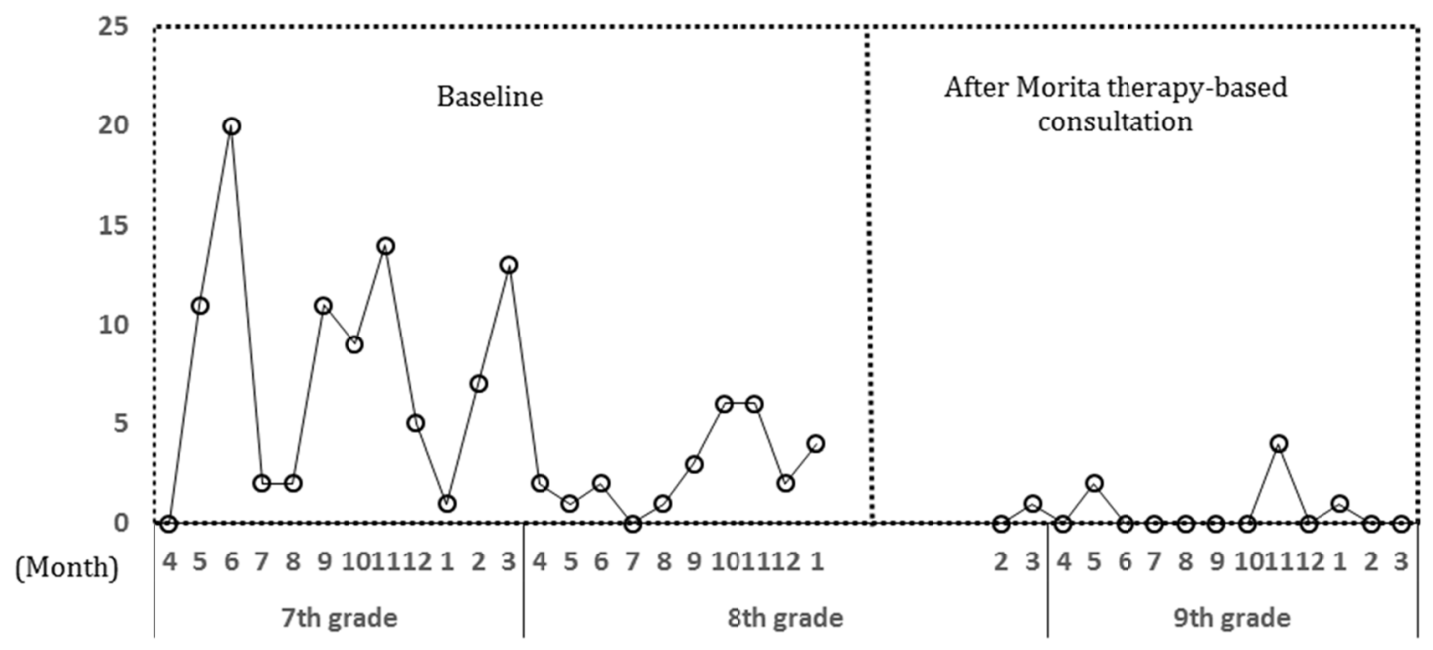

Figure 1. The number of full-time absence 
Table 1. Student A's body temperature in the morning

\begin{tabular}{cc}
\hline day 1 & normal temperature \\
day 2 & normal temperature \\
day 3 & normal temperature \\
day $\mathbf{4}$ & 40.0 degrees $\mathrm{C}$ \\
day $\mathbf{5}$ & 38.5 degrees $\mathrm{C}$ \\
day $\mathbf{1 1}$ & 39.0 degrees $\mathrm{C}$ \\
day $\mathbf{1 2}$ & normal temperature \\
day 13-day 21 & normal temperature \\
\hline
\end{tabular}

\section{Discussion}

This uncontrolled case study demonstrated the effectiveness of Morita therapy-based consultation for a school-refusing adolescent suffering from somatic complaints. Initially, Student A was absent from school, due to mild somatic complaints that gradually increased over time. Thus, Student A and her mother visited the psychiatric clinic, where they were advised to stop attending school until her somatic complaints were either reduced or eliminated. However, her psychogenetic fever persisted, even after she remained at home for a certain amount of time. Subsequently, a gradual school-return approach was implemented for approximately 10 months. However, this approach failed to alleviate the somatic complaints and improve Student A's school attendance. It was also suggested that these conditions were caused by Student A's mood-based attitude toward school attendance. After the consultation with the parents, they understood Student A's fixation on somatic complaints and school non-attendance as avoidance behaviors. Subsequently, Student A's behavior changed from a mood-based attitude into a purpose-based attitude following the Morita therapy-based approach.

In this case, Student A and the parties concerned were fixed on her somatic complaints, even after she was diagnosed with no particular medical problem. This situation reinforced her school refusal and psychogenetic fever, rather than alleviate them. Moreover, this obsession, according to her mood-based lifestyle, prompted Student A's psychic interaction, which in turn, influenced her school refusal and somatic complaints. Thus, to eliminate this cycle of psychic interaction, it was necessary for Student A and the parties concerned to stop focusing primarily on her symptoms and simply accept them while attending school.

Based on the Morita therapy approach, Student A had no choice but to attend school without attempting to control her neurotic symptoms. During the consultation, this in vivo exposure was significantly stressed. The parents, as the facilitators, understood and agreed to encourage their daughter to return to school. In fact, when the parents told their daughter about Morita therapy and its approach, Student A stated that she had also been thinking about doing something to remedy the situation. This indicates that Student A recognized that she could not attend school on a regular basis, while continuing to focus on her somatic complaints. The day after the consultation meeting, Student A resumed regular school attendance, after which her psychogenic fever became afebrile after several days. In addition, through the Morita therapy-based consultation, Student A changed her mood-based attitude into a purpose-based attitude that eventually improved her overall school attendance and eliminated her somatic complaints. Overall, it may be difficult for therapists to make clients and parties concerned understand the Morita therapy-based approach, since its therapeutic approach completely differs from that of other approach. Moreover, the concept that patients should continue their routine activities, while continuing to suffer from somatic symptoms seems rather harsh. However, in the present case, Student A's parents (especially the father) strongly agreed with this approach and implemented the plan as soon as possible.

Apart from the effectiveness of Morita therapy-based consultation for school refusal, this study found two interesting points. First, this approach can prevent school-refusing adolescents from prolonging their non-attendance, especially when the intervention is implemented at an early stage. In this regard, previous studies have shown that prolonging school non-attendance can increase the refuser's anxiety about returning to school (Terada, 2015; Waeneche, 1964) and reduce their motivation to resolve such aversion to school. Thus, the Morita therapy-based approach may also be effective for dealing with such aspects.

Second, this approach can contribute to school refusal prevention and education. School refusal in Japan has become a serious issue in compulsory education, which requires 6 years of elementary school (ages 6-12) and 3 years of junior high school (ages 12-15) (Maeda, Hatada, Sonoda, \& Takayama, 2012). Concerning the increase in the number of Japanese school-refusing adolescents, one crucial aspect in Japanese compulsory education should not be ignored. More specifically, Japanese students in compulsory education can automatically receive promotion/graduation at the assumed age of promotion/graduation, regardless of school attendance and individual academic achievement (Shinohara, 2008). 
This is based on an ambiguous standard of student promotion/graduation in which a policy of kindness toward school refusers can be implemented by the school principal, who has the authority to make such decisions about a student's promotion/graduation (Shinohara, 2008). In this system, many Japanese children and adolescents may easily develop a mood-based attitude toward school attendance. Thus, parents, specialists, and the parties concerned need to address this issue when it first appears. Moreover, if parents and school staff members become more aware about the effectiveness of Morita therapy, then they could prevent students from becoming school-refusing adolescents with serious neurotic symptoms.

The concept of Morita therapy is rather unique and simple, but it is an extremely practical idea that is not seen in other psychotherapies. For example, in Morita therapy, a person's psychological condition is sometimes compared to the weather; that is, the weather is a natural phenomenon that cannot be controlled by people, and individuals have no other choice but to continue with their daily lives as they adjust for the weather (Morioka, 2005). People's mental conditions are exactly the same as the weather since (at some level) individuals cannot control them and they must find a way to live under such conditions. In other words, anxiety, phobia, or somatic complaints in one's daily life are natural responses, and not disorders that need to be directly treated (Okamoto, 2015).

In the present case, Student A and the parties concerned stopped focusing on controlling her somatic complaints and simply accepted the symptoms and focused on attending school. Again, this process appears to be rather simple, but it is sometimes difficult to implement, due to the burdens of in vivo exposure. Initially, Student A believed that she would attend school when her symptoms disappeared; that is, she still had the motivation to attend school, despite being unable to return to the classroom. However, when her parents told her about Morita therapy, Student A accepted her symptoms, which, in turn, helped her change her cognition and behavior. Hence, her motivation of returning to school was one of the important factors in the process.

It is also important to note that, although Morita therapy can be easy to understand (Kora, 1989), it is sometimes difficult to implement in clinical settings. This is because most clients with neurotic symptoms, especially those who are willing to receive psychotherapy expect some type of treatment that can alleviate some or all their symptoms. This is based on the fact that neurotic symptoms are abnormal phenomena that should be treated in the field of psychotherapy. However, Morita therapy is in direct contrast to this assumption. Therefore, therapists that apply Morita therapy should instruct clients to do the necessary work as a controllable behavior, while accepting their symptoms in a didactic manner, which, in turn, can help alleviate the symptoms.

Finally, although the present study highlighted the effectiveness of Morita therapy-based consultation for a school-refusing adolescent, additional research on a larger sample should be performed to increase the generalizability of the findings. Perhaps, more practical and evidence-based studies in Morita therapy should be implemented in a wider region in which many children and adolescents refuse to attend school for various psychological reasons.

\section{References}

Bernstein, G. A., Hektner, J. M., Borchardt, C., \& McMillan, M. H. (2001). Treatment of school refusal: One-year follow-up. Journal of the American Academy of Child Adolescent Psychiatry, 40, 206-213.

Blagg, N. R. (1987). School phobia and its treatment. London, England: Croom Helm.

Heyne D., \& Sauter, F. M. (2013). School refusal. In Essau, A., \& Ollendick, T. H. (Eds.), The Wiley-Blackwell handbook of the treatment of childhood and adolescent anxiety (pp. 471-517). John Wiley \& Sons.

Heyne, D., \& King, N. J. (2004). Treatment of school refusal. In P. M. Barrett, \& T. H. Ollendick (Eds.), Handbook of interventions that work with children and adolescents: Prevention and treatment (pp. 243-272). John Wiley \& Sons, Ltd.

Heyne, D., King, N. J., Tonge, B. J., Rollings, S., Young, D., Prichard, M., \& Ollendick, T. H. (2002). Evaluation of child therapy and caregiver training in the treatment of school refusal. Journal of the American Academy of Child and Adolescent Psychiatry, 41, 687-695.

Honjo, S., Kasahara, Y., \& Ohtaka, K. (1992). School refusal in Japan. Acta Paedopsychiatrica, 55, 29-32.

Ishiyama F. I. (1983). A case of severe test anxiety treated in Morita therapy: Acceptance of anxiety and not fighting it. Canadian Counsellor, 17, 172-174.

Ishiyama F. I. (1986). Morita therapy: Its basic features and cognitive intervention for anxiety treatment. Psychotherapy: Theory, Research, Practice, Training, 23, 375-381.

Ishiyama, F. I. (1990). A Japanese perspective on client inaction: Removing attitude blocks through Morita therapy. Journal of Counseling and Development, 68, 566-570. 
Ishiyama, F. I. (2003). A bending willow tree: A Japanese (Morita therapy) model of human nature and client change. Canadian Journal of Counselling, 37, 216-231.

Kanahara, S. (2008). Morita therapy in high school. Bulletin of Faculty of Contemporary Social Studies Nagasaki Wesleyan University, 6, 53-62 (in Japanese).

King, N. J., \& Bernstein, G. A. (2001). School refusal in children and adolescents: A review of the past 10 years. Journal of the American Academy of Child and Adolescent Psychiatry, 40, 197-205.

King, N. J., Ollendick, T. H., \& Tonge, B. J. (1995). School refusal: Assessment and treatment. Allyn and Bacon.

Kitanishi, K. (2005). Morita ryohou no kihonteki riron (The basic theory of Morita therapy). Kitanishi, K. (Eds), Morita Ryoho (Morita therapy) (pp. 20-39). Mineruba shobou (in Japanese).

Kora, T. (1989). An overview of the theory and practice of Morita therapy (part 1). International Bulletin of Morita Therapy, 2, 70-79.

Last, C. G., Hansen, C., \& Franco, N. (1998). Cognitive-behavioral treatment of school phobia. Journal of the American Academy of Child and Adolescent Psychiatry, 37, 404-411.

Maeda, N. (2016). School-based behavioural consultation for school-refusal behaviour. International Journal of Psychological Studies, 8, 40-52.

Maeda, N., Hatada, S., Sonoda, J., \& Takayama, I. (2012). School-based intensive exposure therapy for school refusal behavior. Clinical Case Studies, 11, 299-311.

Maynard, B. R., Heyne, D., Brendel, K. E., Bulanda, J. J., Thompson, A. M., \& Pigott, T. D. (2015). Treatment for school refusal among children and adolescents: A systematic review and meta-analysis. Research on Social Work Practice, 1-12.

Miura, M., \& Usa, S. (1970). A psychotherapy of neurosis: Morita therapy. Psychologia, 15, 18-34.

Morioka, H. (2005). Yokuwakaru Morita ryohou (Introduction to Morita therapy). Hakuyousha. (in Japanese).

Nakamura, K. (2005). Morita ryoho niokeru shindan to chiryo mensetsu no susumekata (The way of assessment and treatment in Morita therapy). Kitanishi, K. (Eds), Morita Ryoho (Morita therapy) (pp. 40-53). Mineruba shobou (in Japanese).

Nakamura, K. (2014). Morita therapy for psychosomatic diseases and related area. Japanese Journal of Psychosomatic Medicine, 54, 317-324 (in Japanese).

Ogawa, B. (2013). Desire for life. Xlibris Corporation.

Okamoto, S. (2015). Wasure rareta Morita ryohou (Forgotten Morita therapy). Sogensha (in Japanese).

Ollendick, T. H., \& King, N. J. (1999). Child behavioral assessment and cognitive-behavioral intervention in schools. Psychology in the Schools, 36, 427-436.

Shinohara, K. (2008). Seitoshidou to hou (Student guidance and laws). Shinohara, K. (Eds.), Gakkou no tameno hougaku (Laws for school: toward the development of independent and cooperative school) (pp. 128-154). Mineruba shobou. (in Japanese).

Terada, M. (2015). The Treatment of non-attendance children (11): The framework of the treatment in school. The Journal of Tokai Gakuin University, 9, 101-118 (in Japanese).

Warnecke, R. (1964). School phobia and its treatment. British Journal of Medical Psychology, 37, 71-79.

Wimmer, M. (2008). School refusal. Principal Leadership, 8, 10-14.

\section{Copyrights}

Copyright for this article is retained by the author(s), with first publication rights granted to the journal.

This is an open-access article distributed under the terms and conditions of the Creative Commons Attribution license which permits unrestricted use, distribution, and reproduction in any medium, provided the original work is properly cited. 